\title{
RAPID ONSET NATURAL DisASTERS: The Role OF Financing In EFFECTIVE Risk MANAgEMENT
}

\author{
Insurance and Contractual Savings Practice \\ Financial Sector Operations and Policy Department
}

\author{
Eugene Gurenko \\ Rodney Lester
}

\begin{abstract}
:
This paper provides a conceptual framework for designing a comprehensive risk management strategy for rapid onset natural disasters at the country level, with a particular emphasis on the role of catastrophe loss funding. The paper discusses the key policy and technical issues involved in building financially sustainable catastrophe risk transfer and funding programs in disaster prone countries, and their links to risk mitigation. The paper also deals with the cognitive and political economy issues that are likely to arise and ways to accommodate them.
\end{abstract}

\section{Acknowledgements:}

The authors would like to acknowledge a valuable editorial contribution by Richard Zechter.

\footnotetext{
World Bank Policy Research Working Paper 3278, April 2004

The Policy Research Working Paper Series disseminates the findings of work in progress to encourage the exchange of ideas about development issues. An objective of the series is to get the findings out quickly, even if the presentations are less than fully polished. The papers carry the names of the authors and should be cited accordingly. The findings, interpretations, and conclusions expressed in this paper are entirely those of the authors. They do not necessarily represent the view of the World Bank, its Executive Directors, or the countries they represent. Policy Research Working Papers are available online at http:/lecon.worldbank.org.
} 


\section{Executive Summary}

Rapid onset hazard ${ }^{1}$ events can result in substantial human and economic costs. While the most expensive economic losses occur in developed countries, where the monetary value of exposed assets is higher, the relative impact of natural disasters is typically greater and more disruptive in developing countries ${ }^{2}$. In these countries, infrastructure tends to be less resilient, building standards are lower, and there are fewer mechanisms and less resources available for coping with natural disasters after the event. The $1985 \mathrm{El}$ Salvador earthquake destroyed assets equal to $27 \%$ of national GDP and $158 \%$ of total annual government revenues, and the direct ${ }^{3}$ losses from flooding in Bangladesh in 1998 were equivalent to $17 \%$ of GDP and $152 \%$ of government revenues. ${ }^{4}$

While major hazard events such as those cited above have dramatic but relatively infrequent impacts, a number of developing countries have to cope with the cumulative cost of less severe earthquakes, typhoons and floods that occur relatively regularly. The Philippines is hit by an average of 20 typhoons each year (in addition to being vulnerable to earthquakes and volcanoes), many of which have a serious impact on economic activity in rural areas as well as destroying property and infrastructure in urban areas. Turkey is subject to ever present earthquake risk, with 66 earthquakes of intensity 8.0 or greater recorded in the $20^{\text {th }}$ century even before the devastating Marmara earthquake of 1999. In India from 1996 to 2001, the estimated direct losses from various natural disasters amounted to $\$ 13.8$ billion. ${ }^{5}$ Moreover, the frequency of weather related catastrophic disasters appears to be increasing over time in some regions.

Yet, despite their growing exposures and vulnerabilities to hazards ${ }^{6}$, developing countries retain most of the attendant risk due to the undeveloped state of their domestic insurance markets and a resultant inability to transfer risk to international reinsurance markets. In these countries, less than $1 \%$ of total direct losses from natural disasters is insured, compared with 40-100\% in industrial countries such as the United States or France. $^{7}$ Even the small amount of insurance coverage that is available in practice tends to be limited to major commercial properties in urban areas, with the level of insurance penetration for homeowners and small businesses in most of these countries being negligible. Catastrophe protection for better off homeowners is sometimes present in

\footnotetext{
${ }^{1}$ A hazard is any exogenous event that can destroy capital, including natural perils, epidemic and terrorism.

${ }^{2}$ There is some evidence that natural disasters can, in some circumstances, provide an economic stimulus in industrial countries because of the efficient funding and mitigation mechanisms in place, and the opportunity provided to replace aged infrastructure and facilities.

${ }^{3}$ Direct losses usually refers to the replacement value of property and infrastructure destroyed or severely damaged.

${ }^{4}$ Gurenko, Eugene. "Building Effective Catastrophe Insurance Programs at the Country Level: A Risk Management Perspective" in Catastrophe Risk and Reinsurance: A Country Risk Management Perspective, Risk Books, London 2004. pg. 4

${ }^{5}$ Lester, Rodney and Eugene Gurenko. "Financing Rapid Onset Natural Disaster Losses in India: A Risk Management Approach.” World Bank, August 2003. pg. 1.

${ }^{6}$ Exposure refers to the extent and value of property, infrastructure and lives exposed to hazard.

Vulnerability refers to the response of structures (and their inhabitants) to hazards. Disasters are essentially man made.

${ }^{7}$ Gurenko (2004). pg. 2.
} 
middle-income emerging markets. The key constraint on insurance market development is low per capita incomes, since low-income consumers have less discretionary income, fewer assets to insure, and are expensive for commercial insurers to reach and service. The major determinant of insurance density (premium per capita) is per capita income ${ }^{8}$, and there appear to be few means to circumvent this "iron law" through private markets alone.

In addition, domestic insurance companies in developing markets tend to be undercapitalized and most do not have the capacity to retain exposure to the risk of natural disasters. As a result, whatever limited catastrophe risk coverage they offer has to be largely reinsured through international markets, where pricing has become highly volatile in recent years.

As a consequence of the limited domestic insurance coverage for catastrophic risks provided by local markets, and a lack economic incentives to engage in ex ante risk management, governments generally respond to natural disasters after the fact, relying on donor grants and domestic budgets, including diversion of resources from other planned development projects. Emergency funding for reconstruction has become the linchpin of some governments' strategies for funding disaster reconstruction, more often than not predicated on emergency reconstruction lending programs from the World Bank and other multilateral development banks. While ex post disaster funding from donors and international development banks can be an important part of government catastrophe risk management strategy, over-reliance on this approach has a potential downside, namely an attendant lack of economic incentives for countries to engage in proactive risk management and emergency response capacity building. In a recent study in India, World Bank staff determined that post disaster response capability was as important as the availability of funds in determining the effectiveness with which resources are employed (Chart 1).

\footnotetext{
${ }^{8}$ A power curve applies with insurance consumption rising on average by $1.3 \%$ for every $1.0 \%$ rise in income per capita.
} 


\section{Chart 1 - Gujarat Earthquake - Funds Application}

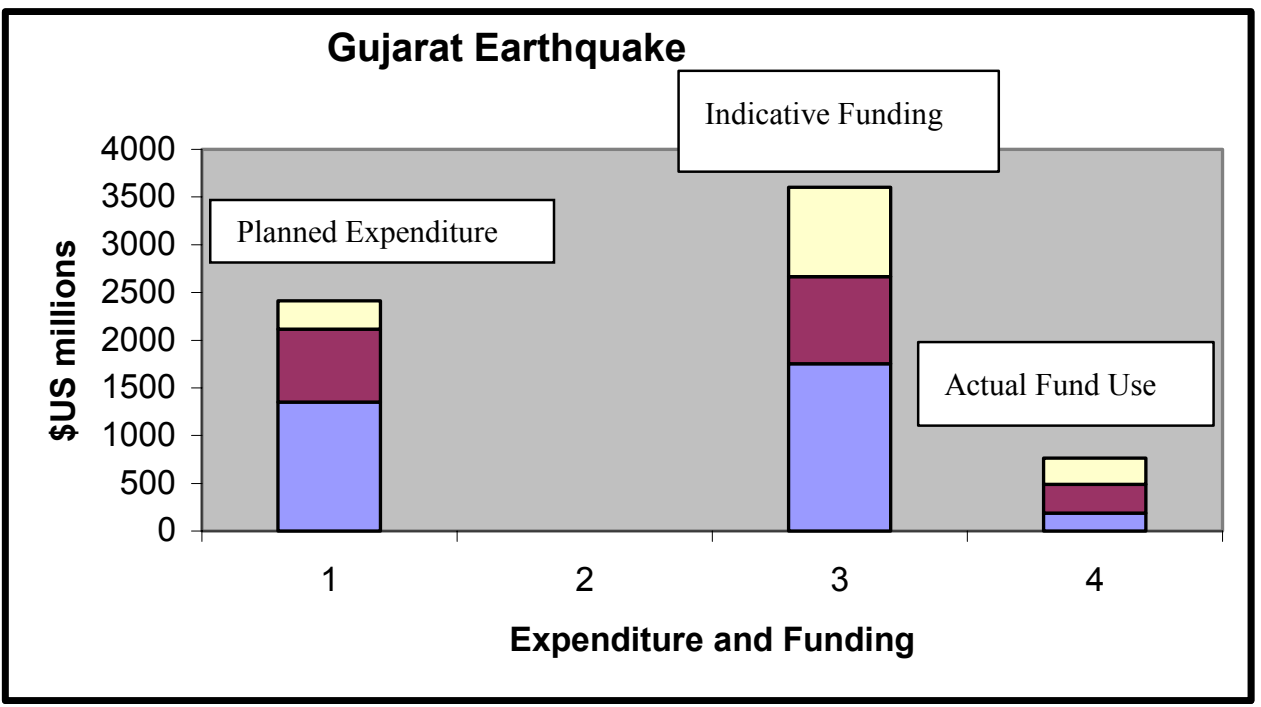

Source: Ministry of Finance, Government of India

In industrial countries, there is both greater private sector insurance capacity to cover catastrophe risks as well as more flexibility to incur fiscal costs for relief and reconstruction. However, even in wealthy countries with well developed insurance markets, the loss potential can be so large or indeterminate that the insurance markets are unable to provide sufficient capacity at acceptable prices. In some of these cases, special state or country-wide mandated catastrophe insurance programs have been developed, usually as a private/public partnership supplementing the private insurance system. Industrial countries and states with such arrangements include France, California, Florida, New Zealand, Norway and more recently Taiwan.

These types of catastrophe insurance pools can play a role in reshaping the way in which developing countries manage rapid onset natural disaster risk. By arranging ex ante sources of risk financing such as insurance, countries (and individual policyholders) can add to the availability of ex post funds and provide access to liquidity immediately following an event. In addition, catastrophe insurance programs can contribute to better risk management through embedding incentives for mitigation in their design, leading in the longer run to reductions in losses, lower fiscal costs of reconstruction and thus improved prospects for investment and economic growth.

The Turkish Catastrophe Insurance Pool (TCIP), initially targeted at earthquake risk, is probably the best known of the more recent efforts in developing countries. It combines elements of the California Earthquake Authority and New Zealand EQC, but with the domestic private insurance sector limited to a distribution role. The World Bank worked with the Turkish government, the domestic private insurance market and international reinsurers to develop TCIP, which is supported by innovative funding mechanisms developed within the Bank. A number of developing and transition countries are considering implementing state mandated catastrophe insurance pools, building on the experience of the TCIP as a useful model for countries with less developed private insurance systems. 
The TCIP itself is subject to ongoing modification based on the lessons of experience. In particular it has become apparent that the pressures on politicians to appear to be doing something for the better off sections of society after a natural disaster, even if a functioning insurance markets exists, cannot always be resisted ${ }^{9}$. Thus safety valve mechanisms need to be built into the system that will not undermine the overriding country risk management effort.

The key elements of the framework proposed to deal with the issues adumbrated in this summary are:

1. Disaster funding approaches that encourage ex ante mitigation efforts (risk management) as well as reinforcing ex post response capacity (coping mechanisms).

2. Three basic and interlinked building blocks:

a. A formal institutional structure (a risk management agency) to guide, support and fund mitigation efforts and response capacity enhancement, particularly with respect to critical infrastructure and the poor.

b. A national capacity to offer catastrophe insurance to better off households and the small business sector. Where insurance markets are undeveloped this may take the form of a separately managed catastrophe pool, possibly backed by international capital (i.e. reinsurance and catastrophe bonds).

c. A "political economy" facility whereby politicians can be shown to be responding to all affected households after a catastrophe. This will often take the form of a low-interest loan facility for reconstruction costs, including the cost of any post disaster mitigation requirements, and modest relief grants.

3. Techniques to identify gaps between ex post resource availability and post disaster financing needs (particularly for those countries and states with concentrated and vulnerable exposures). Modern technology can enable these to be identified and appropriate ex ante funding strategies developed.

4. Ex ante funding mechanisms designed explicitly to support the building blocks listed above. World Bank contingent credit and reinsurance funding instruments have already taken on this role in a number of countries subject to earthquake risk.

\footnotetext{
${ }^{9}$ This is not confined to developing and transition countries. One recent U.S. president declared a disaster every week for three of the years he was in office.
} 


\section{Introduction}

The purpose of this paper is to develop a risk ${ }^{10}$ management framework for financing capital losses arising from rapid onset natural disasters ${ }^{11}$ in developing countries. The objective is to provide governments and market participants with an analytical approach designed to shift the balance of catastrophe risk management away from ex post, ad hoc responses, in the direction of active ex ante risk management strategies. The philosophy of this paper is well caught by the following quote by a senior U.S. official responsible for flood plain management ${ }^{12}$, while acknowledging the particular circumstances of the poor:

Various legislation (e.g. flood insurance) calls for individuals to bear the full cost for their decision to utilize flood-hazard locations. This... is not happening. Strict enforcement of present measures is needed, with strong penalties for noncompliance. Taxpayers should not be expected to bail out uninsured flood victims. Those who continue to live in hazardous areas with full knowledge of the risk should be expected to suffer the consequences... The federal government must integrate its disaster assistance policies and programs with those that promote longer-term solutions to flood problems. Relief should be linked to responsibility ... Many citizens simply expect public aid when calamity strikes. With 50 federal programs to supplement their courage, people have every incentive to build in flood prone areas and leave it to Uncle Sam.

The structure of the paper is as follows:

- Executive Summary, provides an overview of the topics to be covered, and summarizes the proposed risk management framework.

- Section I addresses the costs of rapid onset natural disasters and the potential weaknesses of prevailing ex post financing responses. It also outlines a conceptual risk management framework for rapid onset natural disasters, including risk measurement, mitigation measures and the role of various risk financing techniques.

- Section II provides an in-depth discussion of risk analysis and measurement techniques that are required in order to develop a coherent risk funding approach.

- Section III describes the range of ex ante risk financing strategies, including catastrophe insurance pools, reserve funds and contingent credit facilities, and how they can be used and combined.

- Section IV outlines the design issues that must be addressed in creating a catastrophe insurance pool, including the legal and institutional framework, the role of government and market participants, incentives for risk mitigation and insurance policy design.

- Section V provides the summary and conclusions, and identifies key issues for consideration in the future as countries strive to manage the growing risk of rapid onset natural disasters.

\footnotetext{
${ }^{10}$ In this context risk means potential for significant loss.

${ }^{11}$ A disaster is the manifestation of risk. It requires a combination of hazard, exposed capital (including human and social capital) and vulnerability of that capital to the hazard.

12 Platt, page 234.
} 


\section{Section I: The Costs of Rapid Onset Natural Disasters in Developing Countries, Limitations of the Existing Coping Mechanisms and an Alternative Approach}

\section{Costs of Rapid Onset Natural Disasters in Developing Countries}

The most massive economic losses from rapid onset natural disasters occur in developed countries, where the value of exposed capital is higher in absolute terms. There have been 15 natural disasters in the United States in the last 15 years that have resulted in a total of $\$ 43$ billion in losses. $^{22}$

However, the relative impact of natural disasters is greater and more disruptive in developing countries, where infrastructure is less resilient, building standards are lower, incentives for mitigation are absent, private markets do not provide catastrophe insurance for homeowners and small businesses, and there are greater constraints on government resources available to cope with disasters. As a consequence, hazard related events cause more loss of life and injury, and the subsequent fiscal and economic consequences are more extensive. Of the 40 worst catastrophes in terms of the number of victims in 19702001,39 occurred in developing countries. ${ }^{23}$

Specific events demonstrate the dramatic impact of catastrophes on developing countries. For example, the toll from the 1999 Marmara earthquake in Turkey was close to 16,000 killed and 44,000 injured, with physical damages of about $\$ 10$ billion or $5 \%$ of GDP, or $21 \%$ of government revenues. ${ }^{24}$ The $1985 \mathrm{El}$ Salvador earthquake destroyed property and

\footnotetext{
${ }^{13}$ A hazard is any exogenous event that can destroy capital, including natural perils, epidemic and terrorism.

${ }^{14}$ There is some evidence that natural disasters can, in some circumstances, provide an economic stimulus in industrial countries because of the efficient funding and mitigation mechanisms in place, and the opportunity provided to replace aged infrastructure and facilities.

${ }^{15}$ Direct losses usually refers to the replacement value of property and infrastructure destroyed or severely damaged.

${ }^{16}$ Gurenko, Eugene. "Building Effective Catastrophe Insurance Programs at the Country Level: A Risk Management Perspective" in Catastrophe Risk and Reinsurance: A Country Risk Management Perspective, Risk Books, London 2004. pg. 4

${ }^{17}$ Lester, Rodney and Eugene Gurenko. "Financing Rapid Onset Natural Disaster Losses in India: A Risk Management Approach.” World Bank, August 2003. pg. 1.

${ }^{18}$ Exposure refers to the extent and value of property, infrastructure and lives exposed to hazard.

Vulnerability refers to the response of structures (and their inhabitants) to hazards. Disasters are essentially man made.

${ }^{19}$ Gurenko (2004). pg. 2.

${ }^{20}$ A power curve applies with insurance consumption rising on average by $1.3 \%$ for every $1.0 \%$ rise in income per capita.

${ }^{21}$ This is not confined to developing and transition countries. One recent US President declared a disaster every week for three of the years he was in office.

${ }^{22}$ Ibid. pg. 5.

${ }^{23}$ Swiss Re, Sigma. No.1 (2002). pg. 23.

${ }^{24}$ Gurenko, Eugene. "Building Effective Catastrophe Insurance Programs at the Country Level: A Risk Management Perspective" in Catastrophe Risk and Reinsurance: A Country Risk Management Perspective, Risk Books, London 2004. pg. 4
} 
infrastructure equal to $27 \%$ of national GDP, or $158 \%$ of total annual government revenues, while the direct losses from flooding in Bangladesh in 1998 were equivalent to $17 \%$ of GDP, or $152 \%$ of government revenues. Even in large countries the impact can be significant; the Gujarat earthquake in India killed almost 14,000 people and injured 167,000 others, causing $\$ 2.1$ billion in damage, equivalent to only $1 \%$ of GDP but a substantial $7 \%$ of state government annual revenues.

While major infrequent catastrophes such as those cited above have dramatic impacts, many developing countries, particularly in Asia and Latin America, have to cope with the costs of earthquakes, typhoons and/or floods that occur relatively more regularly. Although the human and economic losses that occur from these individual disasters may not be large in absolute terms, the cumulative impact can be substantial. For example, the Philippines is vulnerable to typhoons, floods, earthquakes and volcanic eruptions, suffering damages from natural disasters averaging $0.7 \%$ of GDP annually in 1970-2001. In India, more than 360 natural disasters have been recorded over the past 35 years with reported direct losses on public and private economic infrastructure of approximately $\$ 30$ billion (nominal values at then applying exchange rates). It is estimated that, on average, the direct cumulative costs of natural disasters in India account for up to $12 \%$ of central government revenues.

Rapid onset natural disasters of these magnitudes or frequencies typically have a significant adverse impact on growth and development prospects in developing countries, as economic activity is disrupted and resources are diverted from new investment to relief and reconstruction. Many of these disasters have a disproportionate impact on economic activity in rural areas, which have smaller economic and social safety margins. These sections of society tend to be heavily reliant for day to day survival on lifeline infrastructure such as safe water and roads, and not to have immediate access to available emergency response mechanisms.

Moreover, the frequency of weather related catastrophic disasters appears to be increasing over time, while the economic impact of these events is becoming more devastating as developing countries continue to increase their overall exposures. For example, the reported frequency of natural disasters in India has been increasing over time, with the number of events about 50\% higher during 1981-95 (181 events or 15 per year) compared with $1965-80$ (121 events or 8 per year). This trend has continued with 75 events reported in 1996-2001. While there appears to be a pattern developing of more frequent hydro-meteorological hazards, the biggest impact on the rise in losses over the last 30 years has been the increase in risk exposures due to a rapidly growing

${ }^{25}$ Gurenko, Eugene. "Building Effective Catastrophe Insurance Programs at the Country Level: A Risk Management Perspective" in Catastrophe Risk and Reinsurance: A Country Risk Management Perspective, Risk Books, London 2004. pg. 4 
concentration of people and assets in highly disaster prone urban areas. ${ }^{26}$ The potential for higher losses will continue to rise with further urban development. ${ }^{27}$

\section{Limitations of Ex Post Financing Responses}

In most developing countries insurance markets are not well developed and coverage for natural disasters is very limited. In practice, hazard risk coverage tends to be limited to major industrial and commercial properties. Hazard insurance for homeowners (other than terrorism) is sometimes present where property rights have been established, but is usually restricted to upper-income households.

As a consequence of limited fiscal resources, cognitive and related political economy issues (see Box 1), and very low insurance penetration, governments have generally responded to natural disasters after the fact. Typically this means relying on domestic budgets, including diversion of resources from other projects, and on extensive financing from international donors. Mobilizing emergency funding from external donors has become the linchpin of some governments' strategies for funding disaster reconstruction and has become a major component of lending programs for the World Bank and other multilateral development banks.

\section{Box 1: Cognitive and Political Economy Issues}

Research has demonstrated that most people are not rational when dealing with low probability events and often make poor decisions in dealing with them. The nature of a risk can be important in determining a response. For example a dread factor has been found with certain risks such as the possibility of cancer or nuclear accident which tends to increase their subjective probability. Natural disasters on the other hand tend to be discounted. The U.S. Insurance Research Council found in a 1996 study that while $95 \%$ of U.S. houses are insured for common perils like fire, only $20 \%$ of homes exposed to flooding are insured against floods (see Box 2.). Reasons given for this include certainty equivalents which are less than the insurance premiums required to remove them (i.e. people underestimate the probability and severity of a loss, unless an event has occurred relatively recently), overestimation of the response of their fellow citizens and government and lack of awareness of the availability of insurance (which is sometimes heavily subsidized for those most at risk). In the US people exposed to flood clearly overestimate the amount of ex post federal aid available, much of which is in the form of loans from the Small Business Administration. Flood insurance coverage, which is subsidized, normally provides much better ex post indemnities. In countries with disaster laws that ostensibly make housing good after a disaster (usually earthquake), people are often still living in tents many years after the hazard event.

Even where insurance is available, politicians are often caught between conflicting forces. Not only do they have an imperative to be seen to be dispensing money to victims after a disaster, but often the construction industry has a strong lobby, not least because of the importance of this industry to economic activity. When housing shortages exist the political discount rate becomes even higher. Thus while the statistical and physical measures underlying insurance pricing can demonstrate the level of risk in certain locations they can also be seen as a threat to development within the electoral cycle. Some cities, even in industrial countries, have been known to suppress flood maps for this reason. One of the authors was publicly chastised in parliament in his home country for sponsoring a study of cyclone risk in a state subject to such hazards, but also with a burgeoning tourist and retirement sector.

${ }^{26}$ IFRC, World Disaster Report, 2001

${ }^{27}$ Swiss Re, Sigma. No. 2 (2003). pg. 13. 
Over time, the extensive reliance of developing country governments on donor assistance, combined with the willingness of donors to provide emergency grants and loans, has created an environment in which countries that are prone to disasters have few or no incentives to take proactive measures to manage disaster risks. While ex post disaster funding is an important element of a risk management strategy, over-reliance on this approach by both governments and donors provides no incentives for the implementation of policies to reduce risks (such as better urban planning, higher construction standards, etc.).

In the authors' view this approach is becoming increasingly unsustainable. Over time, as developing countries accumulate more assets (buildings, infrastructure) in limited geographic spaces, their potential loss exposure increases. With sub-standard construction and land-use practices, and the propensity of some regions to experience more natural disasters, the level of countries' vulnerability and risk exposures also increases. These two factors together point to the likelihood of growing real losses from natural catastrophes in the future. Moreover, the capacity and willingness of donors to fund disaster relief and reconstruction is ultimately constrained ${ }^{2833}$. Therefore, funding gaps between available donor resources and post-disaster funding needs are likely to appear (or grow if already present) if disaster prone countries continue to rely on ex post donor funding without engaging in ex-ante risk management, including risk financing.

In addition to being potentially unsustainable, experience across a broad range of countries has demonstrated that an over reliance on reactive, ex post approaches to natural disasters can be sub-optimal. Ex post funding approaches are subject to the following risk enhancing possibilities:

Slow release of funds. Multilateral post-disaster reconstruction aid can take a relatively long time to be negotiated and to disburse, relaxed requirements notwithstanding. Perhaps more importantly there is strong evidence that some disaster related loans have not disbursed because of a fundamental lack of local human and institutional capacity to deploy the available funds. Regardless of the cause the human impact and the level of disruption of economic activity may be far greater due to a delayed response.

Ineffective use of funds. Resource allocation after a catastrophe may be partly ad hoc (and subject to political agendas) due to extreme urgency, which often precipitates a lack of public scrutiny and leaves ample room for political considerations in determining postdisaster investment priorities. For example, in some countries, governments have committed to incur the costs of rebuilding destroyed housing, regardless of the economic status of the owners. This diversion of limited fiscal resources away from productive development projects which are likely to restore economic activity and support the poor can have longer-term adverse economic and poverty effects.

\footnotetext{
${ }^{28}$ See data in the IMF's paper "Fund's Assistance To Countries Facing Exogenous Shocks", August 8, 2003
} 
Insufficient funds. Most developing countries face ongoing fiscal constraints. The quantity of funds available for relief and reconstruction may not be adequate, even with additional borrowing and grants from the donor community, leaving a 'resource gap'. Such a funding gap has negative implications for the provision of public services, particularly if the post-disaster resources are insufficient to restore existing lifeline and health services infrastructure. Longer-term impacts can also emerge from disruption to educational and social infrastructure.

\section{A Rapid Onset Natural Disaster Risk Management Framework}

In light of the limitations of ex post disaster financing strategies, countries that are prone to natural disasters should have a strong interest in developing better policies and tools to take a more proactive approach to natural disaster risk management. In essence, countries should look at their risk exposures on a systematic basis and determine the amount of risk they can retain versus the risk that should be transferred based on their financial profile. A strategy should then be developed to:

- Mitigate risk exposures to reduce the overall expected losses,

- Improve disaster response planning and capacity, including more effective targeting of ex post relief and reconstruction funds,

- Explore ex ante risk funding and risk transfer techniques to limit reliance on ex post donor funding sources, to secure more immediate liquidity post event and introduce incentives for active risk management.

The basic elements of a risk management framework are as follows:

- The first step involves utilizing risk measurement and analysis techniques to assess potential losses from natural hazards. This requires the collection and analysis of data related to the probable occurrence of natural disasters and the calculation of severity of loss and likely damage that would result.

- The second step is to determine how an array of risk reduction techniques (mitigation) can be used to reduce the identified loss exposures. Reducing the loss from future catastrophic events should be an essential part of any risk management program; the most beneficial mitigation programs are those that are done before or at the time of new construction.

- The third step is to determine the most effective risk funding and risk transfer mechanisms, allowing for longer-term economic and social imperatives. Part of this analysis involves calculating the difference between expected losses and available ex post resources, the potential "resource gap". Another key step is to assess the appropriate balance between ex post and ex ante funding mechanisms.

- The final and fourth step is to examine the legal and institutional framework for disaster response and ex post funding. Policies and institutional arrangements 
should focus on coordinated, advance planning for disaster response at various government levels. Fiscal resources can be used to provide incentives for government units at all levels to implement mitigation measures, and to develop the capacity and safeguards to required to employ ex post funding sources effectively.

Ex post sources of funding include redirected budget, direct aid, tax increases, diverted loans (usually involving the development banks), and increased borrowings, including from the central bank. In choosing between these sources of funds, the government will have to assess the costs and benefits of shifting resources and priorities from planned expenditures to disaster response, as well as calculating the macro impacts of incurring additional debt.

Ex ante funding techniques include the establishment of insurance reserve funds (backed by hedging instruments such as reinsurance), inter-temporal smoothing (finite reinsurance), risk transfer (usually specialized catastrophe insurance and reinsurance), and the arrangement of contingent debt facilities. Some countries, including India, Mexico and the Philippines, have established calamity funds (typically as budget line items) with annual appropriations to deal with the ongoing risk of smaller, more frequent disasters.

Calculation of the difference between ex post funding sources and expected losses, the resource gap, will provide insight into the potential value that can be gained by utilizing ex ante financing techniques. While these market based approaches to funding natural disasters can appear to be costly, they may still be more efficient than relying on internal budgetary resources to finance the peak potential hazard related losses of the country, which may be grossly insufficient.

Based on such analyses, some countries and states have developed special state mandated catastrophe insurance programs, usually as a private/public partnership supplementing the private insurance market. These programs provide coverage to homeowners (and possibly small businesses) for specific catastrophe risks. Industrial countries and states with such arrangements include France, California, Florida, New Zealand, Norway and more recently Taiwan (China). The Turkish TCIP, initially targeted at earthquake risk, is the first state mandated catastrophe insurance pool established in a developing country. 


\section{Section II: Risk Measurement and Analysis}

The first step in developing a catastrophe risk management strategy is to perform a loss risk assessment. The result of this analysis provides an objective estimate of potential losses and helps to focus the global risk management effort. It will also facilitate the calculation of the pure risk premium and market clearing premium for risks covered by a catastrophe insurance pool.

A loss risk assessment has four stages:

- Hazard module. First, the natural disasters and geographic areas to be studied must be selected. The characteristics of historical events and physical models are utilized to generate stochastic events using simulation techniques. The hazard module then analyzes the intensity of the event (e.g. ground shaking in an earthquake; peak winds in a typhoon) at specific locations when a stochastic event has occurred.

- Exposure module. Next, the exposed asset base is estimated for each location using available property data or is derived from population distribution data. The exposure model calculates the value exposed by multiplying the building stock by the average building replacement cost.

- Vulnerability module. Third, the vulnerability model is used to calculate the damage to each type of building from a given intensity event at a specific site. Building classifications are based on factors such as construction material and type, usage, number of stories and age. A damage ratio is calculated relating the repair cost to replacement cost for each peril at various intensities and locations.

- Loss analysis module. Fourth, the damage ratio from the vulnerability module is multiplied by the value of the exposed risk at a location to calculate an estimated dollar loss. Results are calculated for each type of property at each location and then locations are aggregated as required to arrive at the estimated loss.

There are five key measures of loss risk that can be derived from the data produced through the loss risk assessment.

- Average annual loss is the expected loss per year when averaged over a very long period. This is the amount that governments ideally would budget for in planning disaster response strategies under Arrow Lind assumptions. $^{29}$.

${ }^{29}$ Arrow, 1970 
- Probable maximum loss is the largest likely loss to housing and infrastructure in a given region from all perils resulting from a single catastrophic event for a given return period ${ }^{30}$. This measure is used by insurance professionals as an estimate of loss severity in determining reserves and other forms of claims paying capacity needed to finance a catastrophic loss.

- Loss exceedance curves are utilized to calculate 1) the probability that all losses in one year could exceed a certain monetary threshold, and 2) the probability that one event in a particular year could exceed a certain value. Also, these curves are used to calculate the probabilistic estimate of average annual loss, which is a basic input into deriving insurance premiums. An example of a loss exceedance curve in provided in Figure 1.

- Pure risk premium is the portion of the insurance premium that is, when aggregated with pure risk premiums from other risks, intended to pay for cumulative losses of an insurer or reinsurer. The pure risk premium is generally expressed as the average annual loss per 1000 dollars of exposed value.

- The market value premium is the cost of transferring the total risk to the private insurance and reinsurance market, which is typically a 3-6 multiple of the pure risk premium. The market value premium adds expenses, underwriting and loss adjustment costs, profit, cost of capital reserves, and inflation to the pure risk premium. ${ }^{31}$ A reinsurer will calculate the impact of providing coverage for a specific risk on its overall portfolio of risks to determine the marginal capital costs incurred, as well as the marginal impact of the risk on overall portfolio returns.

Policymakers in developing countries face challenges in employing loss estimate models. The key difficulty is in obtaining reliable scientific data about hazards, such as earthquake fault characteristics and flood mapping data. In addition, data on property types and values may not be available or specific enough to be useful. Finally, there is often little information on the vulnerability of different building types. Each of these limitations introduces uncertainties into the loss estimate methodology and increases the dependency on expert opinion in loss estimation. Finally, the cost of developing and maintaining loss models can be high. ${ }^{32}$

\footnotetext{
${ }^{30}$ The inverse of probability of occurrence.

${ }^{31}$ Walker, George. "Catastrophe Risk Models for Asia from a User Perspective" in Catastrophe Risk and Reinsurance: A Country’s Risk Management Perspective. Risk Books, London (2004). pg. 3.

${ }^{32}$ Ibid. pg. 6.
} 
In Turkey, for instance, extensive earthquake risk modeling was carried out with technical assistance funding from the World Bank to prepare the launch of the TCIP. Experience has shown that sound risk modeling reduces the uncertainties (and reinsurance costs) involved in estimating and allowing for risk for international reinsurers and thus can help bring down the cost of reinsurance for developing economies.

Figure 1. Loss Exceedance Curve

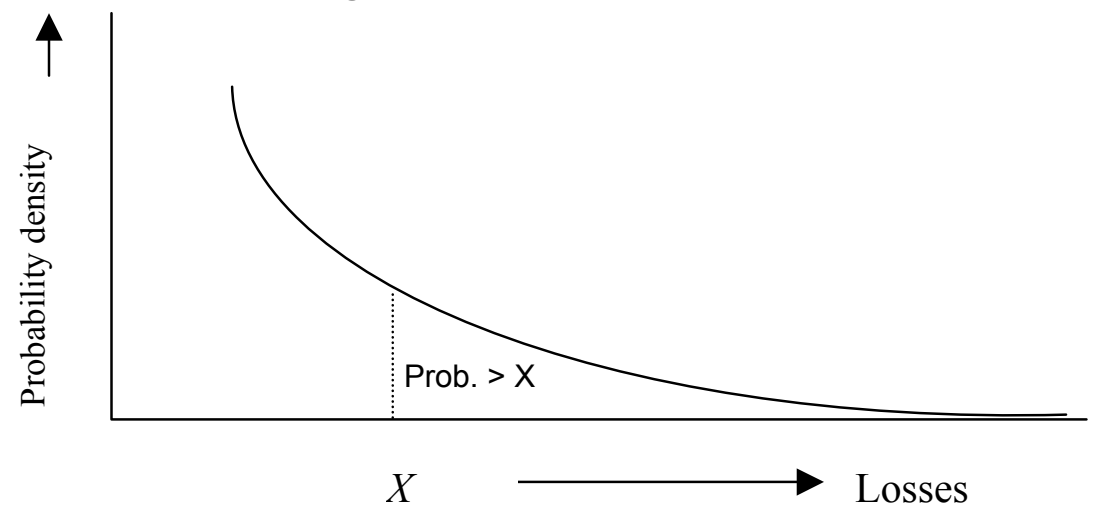




\section{Section III. Ex Ante Funding Techniques -- Catastrophe Insurance Pools}

Once loss estimates have been calculated, they can be used to determine whether ex ante risk financing and risk transfer techniques would be effective in meeting any resource gap left after cost effective mitigation measures are instituted.

For housing and other private sector risks, and in the absence of an effective insurance market, catastrophe insurance pools turn out to be a better funding solution than reserve funds for infrequent (one in 100-250 years) events. Aside from the economic inefficiencies involved in governments bailing out those who could afford insurance (assuming it is available at a fair and efficient price), it is unrealistic to expect governments to create reserves that could accumulate over such a long period without these funds being subject to other more immediate (and sometimes legitimate) claims. It is also unrealistic to expect private insurance companies to build up special catastrophic reserves for severe but unlikely events in the absence of tax and accounting incentives and given the reality of shareholders' shorter-term business planning horizons. Thus reinsurance and other capital market instruments often prove to be the most efficient risk funding mechanism available. Contingent debt facilities can also be a useful tool for financing catastrophe pool loss exposures, particularly in the first years of operation, when a rapid build up of surplus (i.e. de facto capital) is required. Contingent debt can also help such funds to ride out the volatile reinsurance pricing cycle (See Annex II, Annex III).

Government reserve funds and other inter-temporal smoothing devices, such as calamity relief funds found in Mexico, India and the Philippines, can play a legitimate role in funding government exposures to critical infrastructure loss and social obligations to

the poor after a disaster. Here again contingent debt can supplement market risk transfer instruments. If combined with a sound disaster planning framework and appropriate incentives for risk management, this type of ex ante appropriation of funds can result in faster, better targeted disaster assistance than ad hoc post-event responses.

The emergence of this insurance and contingent debt based model for ex ante funding of catastrophe risk has provided an opportunity for the development of more effective risk management strategies in developing countries. While not all disaster-prone countries will have the right conditions for utilizing a catastrophe insurance pool, each would benefit from a more coherent risk management strategy that explicitly addresses the need for advance planning, mitigation measures, development of response capabilities and alternative market-based funding strategies (Box 2). 


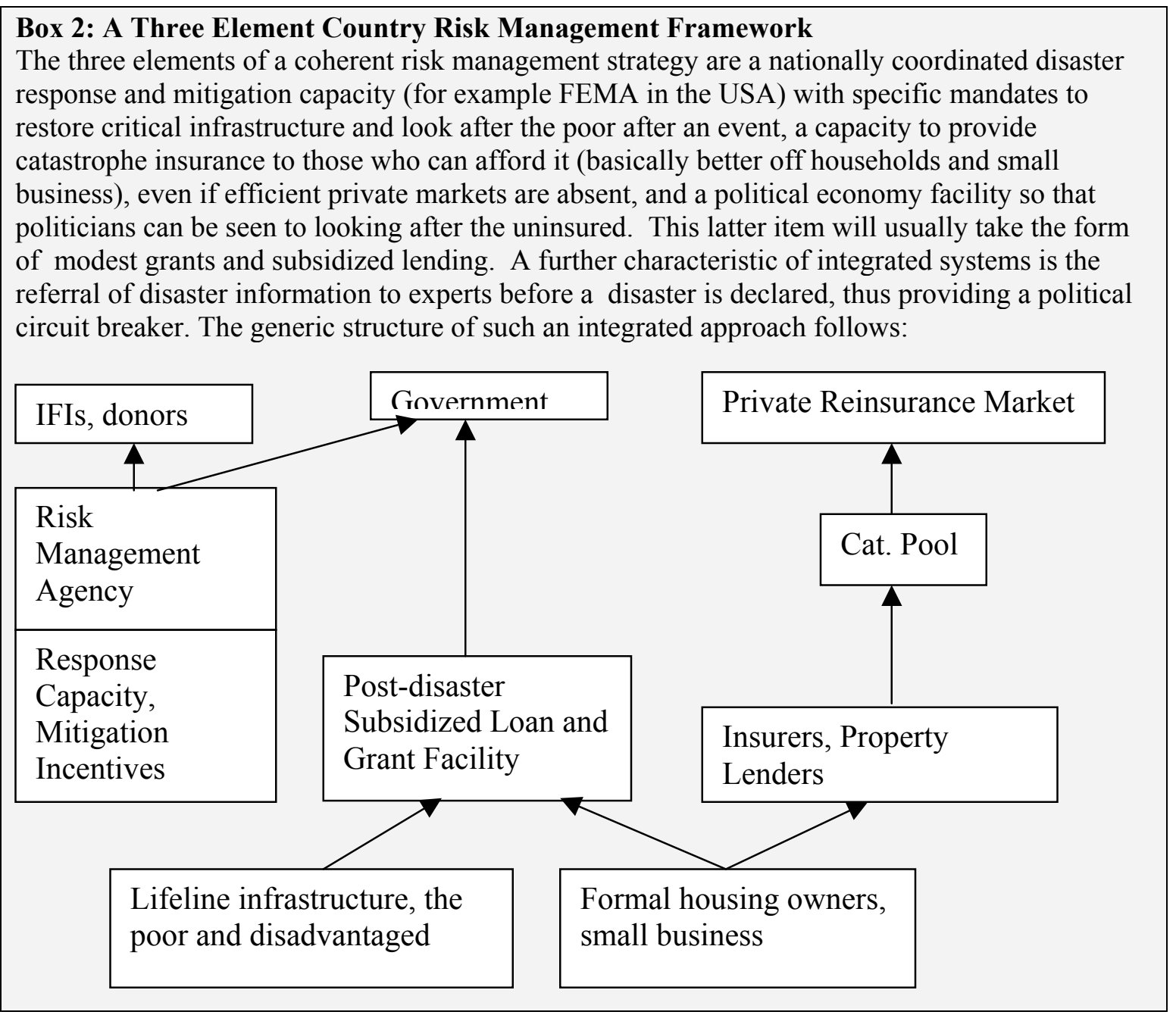

The remainder of this section of the paper provides a closer look at experience to date with insurance pools, because of their potential to have a fundamental role in reducing governments' contingent liabilities to those who should be able to care for themselves.

\section{$\underline{\text { Rationale for State-Mandated Catastrophe Pools }}$}

Rapid onset natural disasters can cause extremely large losses to national or regional economies and the costs may be well in excess of what government resources can finance. Potentially huge losses are more difficult to diversify and therefore insure using domestic insurance capacity. International reinsurance companies with global risk portfolios thus play a key role in the catastrophe risk market, absorbing the catastrophe risk from primary insurers.

In industrial countries, there is both greater private sector insurance capacity to cover catastrophe risks as well as more flexibility to finance unplanned fiscal costs for relief and reconstruction. However, even in wealthy countries with well developed insurance 
markets the loss potential can be so large that the insurance markets are unable to provide sufficient capacity at acceptable prices. Following a major loss, reinsurers often require substantially higher premiums to cover the same risk, in essence reducing or withdrawing cover through price increases. This effect, combined with the cyclical capacity levels found in reinsurance markets, translates into highly volatile pricing for catastrophe risk.

Another important rationale for government sponsored insurance solutions is that catastrophe insurance products are not priced on an actuarial basis like normal insurance risks, where the pure premium (before expense and profit loadings) usually dominates the cost structure. In the case of catastrophe insurance, the cost of the economic capital that must be reserved against potential catastrophes can be large compared to the expected loss from a catastrophe. This is particularly the case for international reinsurers underwriting the less frequently affected, but potentially very costly 'upper layers' of catastrophe excess of loss (XOL) reinsurance. Thus even where a high insurance penetration is found there can be significant technical challenges on the supply side of catastrophe insurance markets.

In some countries special government sponsored catastrophe insurance programs have been developed, in response to a perceived market failure, in order to provide affordable insurance coverage (Box 3).

\section{Experience with State-Mandated Catastrophe Pools and Reserve Funds}

To date, 11 national catastrophe risk management programs have been established and operate successfully in 10 countries. ${ }^{33}$ Each of these catastrophe insurance programs emerged following highly devastating natural disasters to address the subsequent inability of the local insurance market to provide affordable catastrophe insurance coverage for a specific peril. Most of the programs:

- Provide regionally-based coverage for dwellings and contents against specific natural hazards,

- Charge premium rates reflecting the characteristics of the risk, with an element of solidarity involved, and generally do not receive direct government subsidies,

- Address mitigation by encouraging retrofitting and safer construction practices through premium discounts,

- Carry out sales and servicing of policies through the established distribution networks of private primary insurance companies and their agents.

These programs also help alleviate political pressure, both from homeowners and mortgage lenders, for allocation of substantial government resources in the aftermath of natural disasters for reconstruction of private housing.

\footnotetext{
33 The most well known of these programs include the TCIP in Turkey, FONDEN in Mexico, the Florida Hurricane Catastrophe Fund, the Hawaii Hurricane Relief Fund, the California Earthquake Authority, the Earthquake Commission (EQC) in New Zealand, Catastrophe Naturelles (CatNat) in France, and Norway's Norsk Naturskadepool.
} 


\section{Box 3: Market Failure and Public Response}

Where effective private catastrophe insurance markets do not exists a number of governments have stepped in to either create the conditions for a private market to emerge (generally by providing government backed reinsurance) or have generated an entirely new proxy market. The French 'Nat Cat' system and the various Florida windstorm schemes have elements of the former, while the US flood insurance scheme and the Turkish earthquake pool have more in common with the latter. The challenge is to make such schemes actuarially viable, which means wide coverage and reasonably fair pricing, while dealing with the political economy realities inherent in the immediate post disaster environment (see Boxes 1 and 2), and encouraging active risk management in the community. The price of not allowing for political necessity can be seen in Turkey, where, following two relatively minor seismic events in 2003, the Turkish Parliament passed special purpose laws in order to release funds for housing reconstruction, despite the existence of TCIP and related prohibitions in an earlier Disasters Decree. Future modification of the Turkish system will need to allow for this reality.

The French and American schemes mentioned above, while requiring adjustment from time to time, have probably come closest to making the necessary trade offs. The original (1982) French system, which ensures that private sector insurers can deliver catastrophe cover, even for hazards deemed to be 'uninsurable', specified 'Risk Exposure Plans' defined by zone and town. In the absence of effective incentives this attempt at planned mitigation failed and in 1995 a new approach was introduced. This imposes rising deductibles on insurance payouts as hazard events repeatedly strike a town which has not engaged in active risk management (known as Risk Prevention Plans). Because public officials do not want to be blamed for reducing claims payments this approach has been far more effective. By 2002 over 8,000 plans had been set up and 3,500 approved, out of 13,000 towns exposed to hazard events.

The U.S. National Flood Insurance Program (NFIP), which was set up in 1968, is managed by the Mitigation Division of the Federal Emergency Management Agency. As with the French system the scheme has a Federal government liquidity guarantee in the event of an extreme event or series of events, although FEMA is expected to pay back any moneys advanced by Treasury. Another commonality with the French system is that few incentives initially existed to take up the program. By the end of 1973 there were less than 300,000 flood policies in force. Congress began to build incentive into the system that year, following serious floods in the early 1970 s.

Key incentives now include a mandatory requirement that flood insurance be purchased before Federally backed property loans are granted in Special Flood Hazard Areas - generally areas subject to a flood return period of less than 100 years. Only communities satisfying certain mitigation requirements may participate in the NFIP in respect of properties which change hands or for new construction or substantial refurbishment. Uninsured flood victims will also usually be required to buy flood insurance as a condition for receiving Federal Assistance, including Small Business Administration loans. Today approximately 20,000 communities participate in the flood insurance system, and there are 4.4 million policies in force.

However, because of a systemic overly sanguine view regarding levels of post flood federal support (partly stimulated by the propensity of federal elected officials to undermine state and local government efforts to tie mitigation to payments ${ }^{34}$ ), flood insurance penetration in the U.S. remains lower than under the French system (see Box 1.).

The role played by government typically involves the provision of additional risk financing capacity, either directly (e.g. Japan) or indirectly (e.g. the United States). In the latter case, the government becomes the reinsurer of last resort by default, to be called upon in case of highly catastrophic events for additional claims paying capacity. The challenge in the latter ad hoc model is not to create sufficient moral hazard to undermine the whole risk management effort.

\footnotetext{
${ }^{34}$ See Platt, pages 39 to 42 and 234 to 236.
} 
The government also provides regulatory oversight to ensure that catastrophe insurance pools are managed responsibly, with high quality underwriting and proper investment of capital reserves. The goal is to create a pool that sells an insurance product that is highly likely to pay out in the event of a catastrophe.

Ideally, a state-mandated or sponsored catastrophe insurance pool should increase the country's catastrophe risk absorption capacity, while not competing with effectively working markets. The objective is to build on the existing market. The World Bank has been adapting the catastrophe insurance pool model to the developing country context so that it can create a proxy market in countries with relatively undeveloped insurance industries. The first practical experience with this initiative was the TCIP where the World Bank worked with the Turkish government, private insurance markets and international reinsurers to develop this earthquake insurance facility. In addition, it has provided a contingent credit and reinsurance premium funding facility to support reserve (capital) build up in the early stages (see Annex III for the relative roles of reinsurance and the World Bank contingent credit facility in TCIP's 2004 risk funding/ transfer program).

The TCIP was created in the aftermath of the 1999 Marmara earthquake to:

- Make liquidity readily available to owners of residential properties destroyed or damaged by an earthquake to repair or replace their dwellings.

- Reduce the Turkish government's fiscal exposure and the risk to the economy due to major earthquakes.

- Reduce the government's financial dependence on the World Bank and other donors' financial assistance in the aftermath of major earthquakes.

- Encourage appropriate building standards for housing.

The TCIP's earthquake insurance cover is legally compulsory ${ }^{35}$ for many urban Turkish homeowners (although the compulsion is not well enforced). The pool provides cover up to approximately $\$ 50,000$ (at current exchange rates) for each dwelling for a premium that varies across the country depending upon seismicity of the area, and the type and quality of housing construction. Local insurers act as distributors of the TCIP policies and provide additional coverage in excess of that offered by the pool. Since its inception in 2000, the TCIP's penetration ratio has averaged about $17 \%$, the highest among all known programs in terms of overall national catastrophe insurance penetration for homeowners. As with the U.S. flood and French Cat Nat experiences ongoing refinements will be required to provide the appropriate incentives for more homeowners to sign up.

\footnotetext{
${ }^{35}$ While compulsion often runs against pure economic doctrine it is seen as being desirable in certain circumstances where a clear and evident public good exits and significant positive externalities are generated. Examples in the insurance world include compulsory workman's compensation insurance and compulsory motor third party bodily injury insurance. In the authors' experience the argument for compulsion in the case of catastrophe insurance is dependent on the country context. Where the risk is high, fiscal pressures are growing and insurance awareness is low there may be grounds for mandating insurance for registered property, or at least mortgaged property.
} 
Since the TCIP was established, a number of other disaster prone countries have approached the Bank for advice and support. Identification and pre-identification programs are under way for the creation of similar catastrophe risk insurance programs in disaster prone countries countries in Central Europe, Latin America, East Asia and South Asia . 


\section{Section IV. Catastrophe Insurance Pool Design ${ }^{36}$}

The design of catastrophe insurance pools should focus on developing a structure that provides affordable catastrophe coverage of acceptable credit quality and contributes to increasing overall insurance penetration in the local market. This can be achieved by relying on an efficient and low cost distribution mechanisms and securing access to international reinsurance market and other sources of funding. The design process involves a broad range of issues that fall into four major categories:

- Design of insurance coverage. Design of an affordable insurance coverage starts with the identification of perils and exposures to be included in the coverage. The process considers the affordability constraints of the target population, the allowed variation of premiums by risk (the level of solidarity in the premium structure); the level of participation in the program (compulsory vs. voluntary); and other issues of policy design, including acceptable deductibles, limits, extent of coverage, and applicability of co-insurance.

- Institutional structure. The design of the institutional structure entails the determination of the role of government, domestic private insurance companies and international reinsurers in the operation of the program; the establishment of its governance and management structures, as well as the distribution and claims administration arrangements.

- Legal framework. The legal basis for a catastrophe insurance pool should be put in place to provide the incentives for purchasing insurance and undertaking mitigation activities by homeowners.

- Risk financing and transfer strategy. Decisions will have to be reached on the initial pool capitalization requirements and its claims paying capacity; retention of risk by the pool vs. reliance on reinsurance and capital markets; the use of contingent credit arrangements to boost its claims paying capacity to promote survivability; asset management, and the role of the government as a reinsurer/guarantor.

- Mitigation incentives. The two key insurance related mitigation incentives are a credible statement from the authorities that they will only provide modest support to the better off after a disaster occurs and the linking of insurance availability (United States), or insurance payout (France), to mitigation planning and implementation. For such an approach to be viable the authorities need to ensure that an efficient and relatively fair (actuarially) catastrophe insurance market or proxy market exists.

\footnotetext{
${ }^{36}$ A more detailed account of catastrophe pool design features issues is provided in Annex I.
} 
The design process will invariably require iteration among these five sets of issues in order to develop an internally consistent and optimal model for the particular circumstances of the country and risks to be covered. A more detailed discussion of the four above mentioned steps in the program design process follows.

\section{$\underline{\text { Insurance Product Design }}$}

Perils. The initial decision to be made in designing a catastrophe insurance pool is to choose the perils to be covered. This decision can present a challenge in an environment in which there is more than one serious natural disaster risk. Initially, the viability of an insurance coverage for each of the risks should be evaluated separately. Then it can be determined whether to start with one risk and add others later, or to issue a single policy covering both perils.

Exposures. The second key decision is to identify which exposures are to be covered, such as homes, businesses, offices, etc. In addition, it will have to be decided whether to limit coverage to direct losses or expand it to include indirect losses such as business interruption.

Premiums. The next step in product design is the determination of the premium structure. Initially, this would start with the pure risk premium and market value premium as reference points. However, in practice, it is usually the case that the public is not willing to pay the market value premium that would cover all expected losses, including the most infrequent but extreme events that can add significantly to the risk premium. Instead, the starting point is normally to estimate an affordable premium level, then to adjust the policy coverage downward accordingly. Another challenge is to decide the extent to which premiums will be varied by risk, which requires a more complex set of underlying data on vulnerability. Policymakers will also have to determine the degree of solidarity to be embedded in the premium structure, while ensuring that owners of expensive properties pay a premium which is seen to be fair. One tool to avoid moral hazard is to subject claims payments to "average," a form of scaling down. ${ }^{37}$

Homeowners desiring a higher level of coverage can often purchase it through the private insurance market, which tends to service better off segments of population in developing and transition markets.

Participation incentives. An important issue is whether the insurance program will be compulsory or voluntary for homeowners. A compulsory program may be warranted where there is little awareness about insurance and mitigation on the part of the public, where there is a risk of adverse selection or where high enrollment is needed to bring the level of penetration high enough for the pool to be financially viable (also see footnote 32). Voluntary programs require active public education and mass marketing campaigns

\footnotetext{
37"Average" is a method through which claims are scaled down in such a proportion so as to avoid insureds' moral hazard. The payouts to policy holders are calculated according the following formula: Claims Paid = (Maximum Sum Insured/Value of the Property at the time of disaster $) *$ Losses. This process ensures that owners of underinsured property have an incentive to purchase an adequate insurance cover.
} 
to succeed. A key consideration is the tradeoff between achieving wide penetration through a compulsory program and creating a negative perception of catastrophe insurance as a tax.

Coverage. The extent of coverage will then have to be determined taking into account the premium levels, administrative costs and calculations of the costs of adding capacity to the pool through reinsurance and the capital markets (risk financing and transfer strategy). Coverage can be adjusted to market clearing levels through deductibles, limits and maximum payouts. For example, the TCIP policies have a deductible of $2 \%$, exclude indirect losses and damages to movable property, and the maximum payout has recently been raised from $\$ 24,000$ to $\$ 50,000$. These provisions also introduce an element of coinsurance into the equation so that homeowners share some of the risk and potential rebuilding costs. A determination will have to be made whether the coverage should be issued as a stand-alone policy or as an add-on to existing homeowners policies, taking into account the objectives of achieving effective distribution and wide penetration by keeping the costs of catastrophe coverage affordable.

Political economy. It is important that any disaster funding system allows politicians to be visible in a positive way after a disaster occurs. Otherwise the system is likely to be undermined by special laws and other mechanisms designed to enable politicians to release funds over which they have a greater degree of control. Such unplanned fiscal expenditures can often increase the amount of risk in the community and ultimately lead to extreme moral hazard, whereby citizens see no benefit in purchasing insurance or mitigating risk. A better strategy is to acknowledge the political economy reality and institutionalize the political response to disasters so as to minimize any long term detraction from a community's preparedness to deal with risk. One such strategy would be to leave a limited but not insignificant role for government funds in providing immediate post disaster relief, including temporary housing, and subsidized but limited rehabilitation loans, even for the well off (see Box 2.).

Underwriting. The insurance pool manager should also ideally have a mandate to deny catastrophe insurance coverage to buildings that are not compliant with the building code. In practice this raises difficult issues in a post disaster environment, and a better approach, assuming reinsurer support is available, would be to provide reduced coverage if standards are not being met.

\section{Legal Framework}

If the government is to play a formal role in a catastrophe insurance pool then it will have to establish a legal basis for this activity. Each of the 11 existing state mandated catastrophe pools were established through legislation. The legal framework should spell out the institutional structure of the catastrophe pool, including the governance and management arrangements; the incentives to encourage purchase of catastrophe insurance product where appropriate; provisions for risk based premiums and coverage, and provisions to encourage safer construction practices and better risk mitigation. 
Ideally, such legislation should encourage widespread participation in the program, including if necessary, a legal requirement of compulsory insurance for those who can afford it. The credible elimination of government financed housing reconstruction for those members of society with access to insurance markets (whether private of government sponsored), together with introduction of risk based premiums ${ }^{38}$ and policy coverage limitations that allocate some of repair and reconstruction costs to the insured would, over time, create incentives for homeowners to undertake mitigation measures ${ }^{39}$.

\section{$\underline{\text { Institutional Structure }}$}

A key design challenge is to determine the respective roles of government, domestic insurance companies and international reinsurers in the operation, financing, management and governance of a catastrophe pool. How these are determined will depend on circumstances in the insurance market, including an assessment of the strength of the domestic insurance industry as well as the government's fiscal position. Presumably, the government is involved because the private insurance markets are unable to provide sufficient cover at an affordable cost. The government has a significant role to play in governance and regulatory oversight of such insurance entities once they are operational to ensure their financial soundness and fulfillment of social objectives.

The selection of the pool manager is a critical decision that should be taken at an early stage in the design process. This decision will have to be made at the front end so that the managing entity can work with the government team to develop the systems and business relationships that will be needed to launch the pool. The normal candidates for this role would be major domestic insurance and reinsurance companies. For example, the TCIP is managed under contract by Milli Re, the largest domestic reinsurance company in Turkey.

In most developed and some transition countries, private insurers are able to provide some catastrophic insurance cover and the government supplements this by providing additional reinsurance capacity. However, in developing countries it is usually the case that the domestic private insurance industry is undercapitalized and unable to retain any significant part of catastrophic risk. In this environment, the appropriate role for most domestic insurance firms is the distribution of policies and the management of claims. Part of the design process will entail structuring the business relationships and processes between the pool manager and the firms that distribute policies and manage claims in a way that would secure companies' commitment to the program and thus would ensure its success.

The role of international reinsurers is particularly critical to successful design of a risk aggregating mechanism such as a catastrophe pool. The government will have to work

\footnotetext{
${ }^{38}$ Some solidarity can be retained even if premiums are differentiated to reflect risk.

39 In practice governments, in addressing this issue, have found it necessary to phase such measurers in, as many property owners have cognitive problems in recognizing their exposure to disaster risk before a disaster strikes.
} 
with the international reinsurance market at an early stage in the design process in order to assess the terms on which international reinsurers will be willing to accept the risk ceded by the pool. This assessment will be a significant factor in determining the viability of the future enterprise. A broad consultation process involving key reinsurance players will help facilitate a broad consensus on the structure of the national risk aggregator, so that reinsurers will be willing to commit capacity when the program becomes operational.

Governance arrangements for a catastrophe pool should focus on ensuring independence for the board of directors and professional management so that the business viability of the pool is not compromised by political interventions and the pool is well-protected from misuse or confiscation of funds. The composition of the board of directors should represent the interests of the government, the insurance industry and policyholders. The underlying legislation should establish the board's responsibility for setting up the strategy and policies of the pool and for overseeing the performance of management. The Board should be required to disclose information about the pool to the public in order to generate public trust and confidence.

\section{$\underline{\text { Risk Financing and Transfer Strategy }}$}

The risk financing and risk transfer strategy of a catastrophe insurance pool has to optimize the relationship between premium levels, policy coverage and the pool's creditworthiness. The normal yardstick for creditworthiness is that the pool should be able to cover between one in 150 and one in 250 year events (i.e. probability of occurrence in a given year of between $0.67 \%$ and $0.4 \%$ ) without becoming insolvent. As coverage levels increase for a given amount of premium and reserves, the creditworthiness of the pool may deteriorate. However, if coverage levels are set too low in relation to premiums then it will be difficult to achieve sufficient market penetration for the pool to be successful due to the unattractive terms of the coverage offered. The level of coverage in relation to premiums is driven by the pricing dynamics of the global reinsurance industry, as well as by the pool's overheads, and the targeted level of its creditworthiness.

A fundamental issue that pool managers must address is the sourcing of capacity for the pool. The pool sponsor will normally be expected to provide some initial capacity and working capital: and will have to determine how much risk the pool should retain and how much should be ceded to the reinsurance market. Initially, most of the claims paying capacity is likely to come from the international reinsurance market, particularly as the number of participants in the pool grows. Another alternative for adding capacity is the issuance in the capital markets of catastrophe bonds. The pool manager should seek to diversify sources of capacity as well as achieving the best possible pricing terms. However, in order to maintain the creditworthiness of the pool at adequate levels and ensure the affordability of premiums the government will be expected to play a role of reinsurer of last resort by providing additional capacity to the pool on less than market terms; alternatively, it may decide the pool should pay claims on a pro rata basis after an extreme (say one in 500 years) event, which is likely to be politically unpopular with the insureds. 
Catastrophe insurance pools face a particular challenge during the initial years, when the occurrence of a catastrophe before sufficient reserves have been accumulated can easily result in insolvency. An explicit strategy has to be developed to promote survivability of the pool in this transition period, including the optimal amount of risk to be retained. At this point in time a pool needs more reinsurance capacity relative to its own reserves. One useful tool for enhancing the capacity of a pool to withstand an early disaster is a contingent credit arrangement; the TCIP, for instance, is relying on a contingent credit provided by the World Bank. The investment strategy for the pool's reserves is also intrinsically tied to the pool's survivability. For developing countries, particularly smaller size economies, it is prudent for the bulk of the reserves to be invested out of the country to avoid extensive losses on both the liability and asset sides of the balance sheet in case of a large disaster. Finally, the risk financing framework for the pool will have to specify the course of action in the event that a catastrophe renders the pool insolvent and it has to start over. 


\section{Section V. Summary and Conclusions}

The reliance of countries that are prone to rapid onset natural disasters on ex post funding sources, particularly donor assistance, may not be sustainable and in many respects is not optimal from a risk management and capacity building viewpoint. In certain cases such a strategy may adversely affect long-term growth prospects. Fortunately, a set of analytical tools and risk management techniques now exists that can enable countries to establish more systematic, forward looking natural disaster risk management strategies.

For new risk management initiatives to succeed in developing countries, it is essential that they be well designed and managed. This means a coordinated effort among the risk management agency in the country, the insurance and reinsurance sectors, the construction sector and external advisors with established track record in other countries.

A well-conceived national risk management strategy will first entail an analysis and quantification of risk, the establishment of a legal and institutional framework for disaster management, implementation of incentives for risk mitigation and capacity building and, often, the development of appropriate ex ante risk funding instruments, including reinsurance and IFI contingent debt.

Ex ante financing mechanisms provide liquidity immediately following natural disasters and this alone may be sufficient reason to consider them, even if a resource gap does not appear to exist. Catastrophe insurance pools and other risk aggregating mechanisms (including government budget instruments) can provide a convenient institutional setting for developing a risk management approach where insurance markets are incomplete. A well structured catastrophe insurance pool, for example, will achieve affordable premium levels combined with sound insurance policy design; good governance and professional management; effective risk management; and incentives for the private insurance industry to distribute the insurance product efficiently and effectively. 


\section{REFERENCES:}

Arrow, K. J., and Lind, R. C., "Uncertainty and Evaluation of Public Investment Decision." The American Economic Review, 1970, 60: 364-378

Geithner, T. August 2003. "Fund's Assistance To Countries Facing Exogenous Shocks", IMF Working Paper.

Gurenko, E. and Lester, R. August 2003. Financing Rapid Onset Natural Disasters in India: A Risk Management Approach. World Bank Report No. 26844-IN.

Gurenko, E. 2004. "Building Effective Catastrophe Insurance Programs at the Country Level: A Risk Management Perspective" in Catastrophe Risk and Reinsurance: A Country Risk Management Perspective, Risk Books, London.

Platt, R. Disasters and Democracy, The Politics of Extreme Natural Events. Island Press, 1999

Swiss Re, 2003. Sigma. No. 2.

Walker, G. 2004 “Catastrophe Risk Models for Asia from a User Perspective.” In Catastrophe Risk and Reinsurance: A Country Risk Management Perspective, edited by Eugene Gurenko, Risk Books, London 


\section{Annex I. Operation of Catastrophe Insurance Pools}

Project management unit. An important key to success will be establishing implementation arrangements within the government to address each of the steps on the critical path needed to put the pool into operation. Before legislation is passed and the catastrophe pool is established as a legal entity, the government will have to establish an internal unit or working group with responsibility for managing the project. This group should have the participation and support of the insurance supervisor and appropriate government ministries, and include in a consultative process key domestic insurance and reinsurance companies, mortgage lenders and other relevant market participants. Such a group is likely to be hosted by the Ministry of Finance or by the office of insurance supervision.

Selection of pool manager and board of directors. One of the key initial functions of the project management unit will be the selection through a formal procurement process of the pool manager and other advisers that will be needed during the pool design and implementation stage. The unit could also be involved in recommending to the government the membership of the board of directors. Once the pool becomes a legal entity, the board of directors has been formed and the pool manager is selected and contracted, then the government unit can revert to providing occasional support and monitoring the performance of the pool manager in project implementation.

The responsibilities of the pool manager should include implementing the policies set by the board; supervising the distribution of policies through insurance companies; managing claims payments; arranging for risk transfer to the global reinsurance and capital markets; and managing the pool's operations so as to ensure its financial viability. Management of operational matters such as policy processing, information technology, marketing, claims settlements and investments can often be handled most effectively through outsourcing.

Preparation of business plan and budget. Subsequent to the selection of the board of directors and managers of the pool, the manager should focus initially on the preparation of a business plan and budget for the implementation phase of the pool, to be approved by the board of directors.

The design and implementation phase will require the completion of a number of demanding tasks, some of which will necessitate the procurement of expert advice. The establishment of a twinning arrangement between the pool manager and an existing catastrophe pool can be a useful source of expertise and assistance. Engaging specialized consultants will be necessary for some activities.

The key tasks that have to be accomplished include:

Risk modeling and pricing. It may be necessary to conduct additional risk measurement and analysis studies in order to develop loss estimates to provide the basis for premium and coverage calculations. Engineering consultants should analyze and quantify the 
impact of historical and probable future catastrophes, to determine the probable maximum loss and aggregate losses that would occur as a result of these catastrophes. The consultants should work with insurance specialists to present the findings in a way that facilitates risk modeling of catastrophes under varying scenarios, as input to the determination of policy coverage and premiums. This work will also contribute to an underlying natural disaster risk management strategy for the country.

Insurance policy design. The insurance policy design should take into account government proposals, current insurance policy conditions, and available international experience. Consultations with local property insurers and reinsurers and examination of current practices should be undertaken to form a view on structuring deductibles, coinsurance and to develop reliable underwriting guidelines. The financial and fiscal implication of various coverage options should be modeled, with the outputs contributing to the formation of the risk financing and transfer strategy.

Distribution systems. Consultations with domestic insurance companies, agents and loss adjusters should be undertaken to structure their participation and provide incentives for their contribution to the success of the pool, including possible linkages to existing property insurance policies. Contractual arrangements, procedures and information technology linkages for distribution of policies and settlement of claims will have to be developed, building on existing business practices and relationships to the greatest extent possible. If a viable insurance distribution system is not available alternatives, including utilities, tax collection mechanisms, and bank branches, will need to be considered.

Information technology systems. The IT systems should be designed to record in a database the properties that are insured, and to monitor exposure and handle premium transactions with insurance companies and claims transactions with loss adjusters. The system should also have the capability to monitor the exposure of the catastrophe pool, both for risk management purposes and to assist in dealing with international reinsurers and the capital markets. Ideally, the systems will build on those already in use by the insurance industry. The systems should provide both on-line access and call center service, with a back-up system for securing data. If premiums are risk based, software should be developed and required for use by insurance companies and agents to price policies. Insurers, agents and loss adjusters may have to make changes in their own IT systems, and training will have to be provided to them as well as the staff of the pool manager on how to use the pool's IT systems and risk pricing software.

Auditing and monitoring systems. The IT systems will have to be designed to enable monitoring of the functioning, recordkeeping and flow of funds for pool activities, for both the distribution system and for relationships with reinsurers. As part of the development and management of the distribution system, a key challenge will be to establish monitoring systems to ensure that all funds received by intermediaries are remitted in a timely manner to the pool manager. Internal audit processes and reporting procedures to the pool's board of directors will have to be established. 
Risk financing and transfer strategy. The board of directors and manager will likely need expert advice on development of the risk financing and transfer strategy. A reinsurance intermediary should be chosen through international competitive bidding to design a program based on modeling that includes the capacity requirements and structure to achieve the objectives of the pool. The intermediary may also be charged with negotiating with re-insurers and/or capital markets, evaluating the quotations and products offered by the markets, and, following a decision by the board on the strategy, placing the program in the market.

Investment policy and fund management. As the size of reserves grow, asset management becomes increasingly important. A segregated trust or escrow account should be established to hold invested funds for benefit of policyholders to protect them from possible creditor action or other use. The board of directors and pool manager will have to determine a funds management strategy and exercise careful oversight of the investment manager(s) chosen to invest pool funds. An advisor is often engaged in such circumstances to assist the board/ manager develop and implement a long term investment mandate for the pool reserves, to determine fund manager selection criteria and to develop a monitoring approach. A custodian would also have to be appointed to safeguard the assets.

Marketing and public education campaign. A domestic public relations firm should be engaged to develop a marketing and public education campaign that will inform the public about the catastrophe pool before it is launched. The objective of the campaign is to explain and build public confidence in the pool in order to maximize participation by potential insureds. Marketing and public education activities will need to continue after the pool is launched in order to contribute to increasing the penetration of the pool over time.

Liaison with local governments. The pool manager will need to liaise with local governments because property registrations and records at local authorities will form the basis of insurance cover. If the program is compulsory the local tax authorities may be involved in enforcement.

Liaison with structural engineering firms. Catastrophe insurance pools can contribute to the enforcement of building codes through commercial arrangements with independent engineering firms that would be retained to certify the construction quality of new residential dwellings to be insured by the pool. If mitigation incentives in law require inspection and certification of new dwellings, the pool manager will have to establish business relationships with structural engineering firms and arrange for inspections of these dwellings when applications for insurance are received.

\section{Operational Challenges in Managing Catastrophe Insurance Pools}

Once the pool is launched, the government, the pool's board of directors and its management will have to monitor its operations to ensure that it functions effectively and 
meets the objectives for which it was formed. Based on experience, the scheme may need some modifications to improve its operation.

Maintaining/increasing insurance penetration. A key objective is to ensure that the penetration of the program is sufficient to maintain its viability. After some experience is gained, it may be necessary to review the pricing, coverage and distribution arrangements to address impediments to higher penetration rates.

Distribution incentives. Related to the penetration issue, it may be useful to review the business arrangements between the pool manager and insurance companies and agents, including the incentive structure, to ensure that commissions are adequate to motivate them to sell policies, while not set so high that the financial viability of the distribution process is undermined.

Information flows. The operation of the information technology systems will have to be monitored to ensure that information on policies, premiums, claims and payments is properly and efficiently maintained.

Role of global reinsurance companies. The success of the pool will depend on the continued support from global reinsurance companies. Regular communication between the pool manager and reinsurance companies will contribute to this objective.

Management of risk accumulations. As the number of policies grows, the pool manager will have to ensure that reserves and capacity of the pool, including reinsurance and capital market support, is sufficient to cover expected losses.

Many of these operational issues are being addressed in Turkey, where the TCIP has experienced success in its initial years of operation but still faces some ongoing operational challenges. The TCIP rapidly achieved a level of 2.4 million policies in 2001 , or about $20 \%$ penetration, but the number has fallen to 1.9 million policies in 2003 , or $15 \%$ penetration. This is resulting in a slower than planned accumulation of reserves.

For instance, there remains an open issue between the TCIP, which has exclusive rights to issue earthquake insurance policies up to a basic limit defined by the disasters law, and domestic insurance companies. The private insurers would like to integrate the TCIP compulsory earthquake policy into their own homeowners property policies in order to reduce transaction costs and to increase incentives for agents to sell more policies. This, at times, has impeded the full cooperation of the insurance companies with the scheme.

On the positive side, thus far the TCIP has been successful at achieving required levels of reinsurance and has retained the cooperation of the global reinsurers despite the shortfalls in growth in premiums compared to initial projections. From its inception in late 2000, it has already paid out on over 3,300 claims from 47 separate earthquakes, without recourse to reinsurance capacity. In this regard, the scheme has been operating as planned. 


\section{Annex II Catastrophe Reinsurance Pricing Volatility}

$(1984=1.00)$

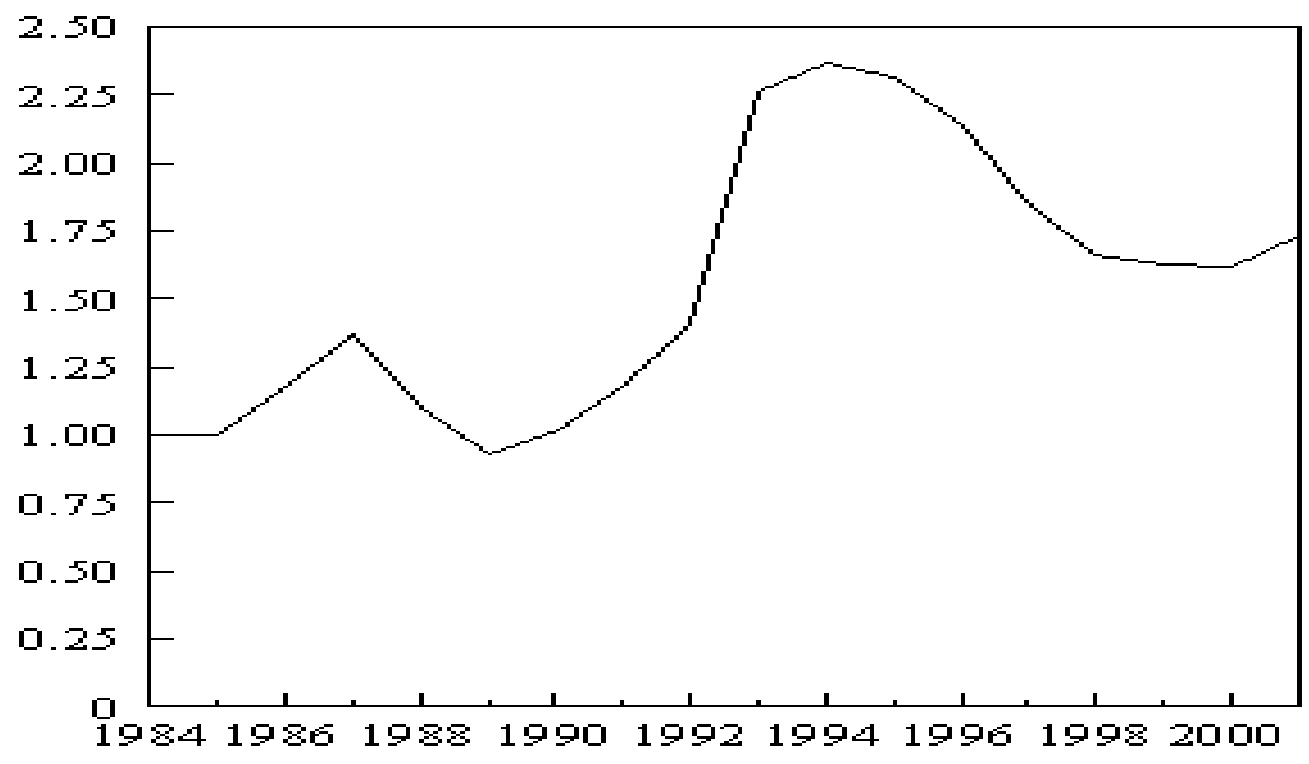

Source: Congressional Budget Office based on data from Paragon Reinsurance Risk Management Services. 
Annex III. Contingent Debt Facility and Reinsurance

TCIP 2004

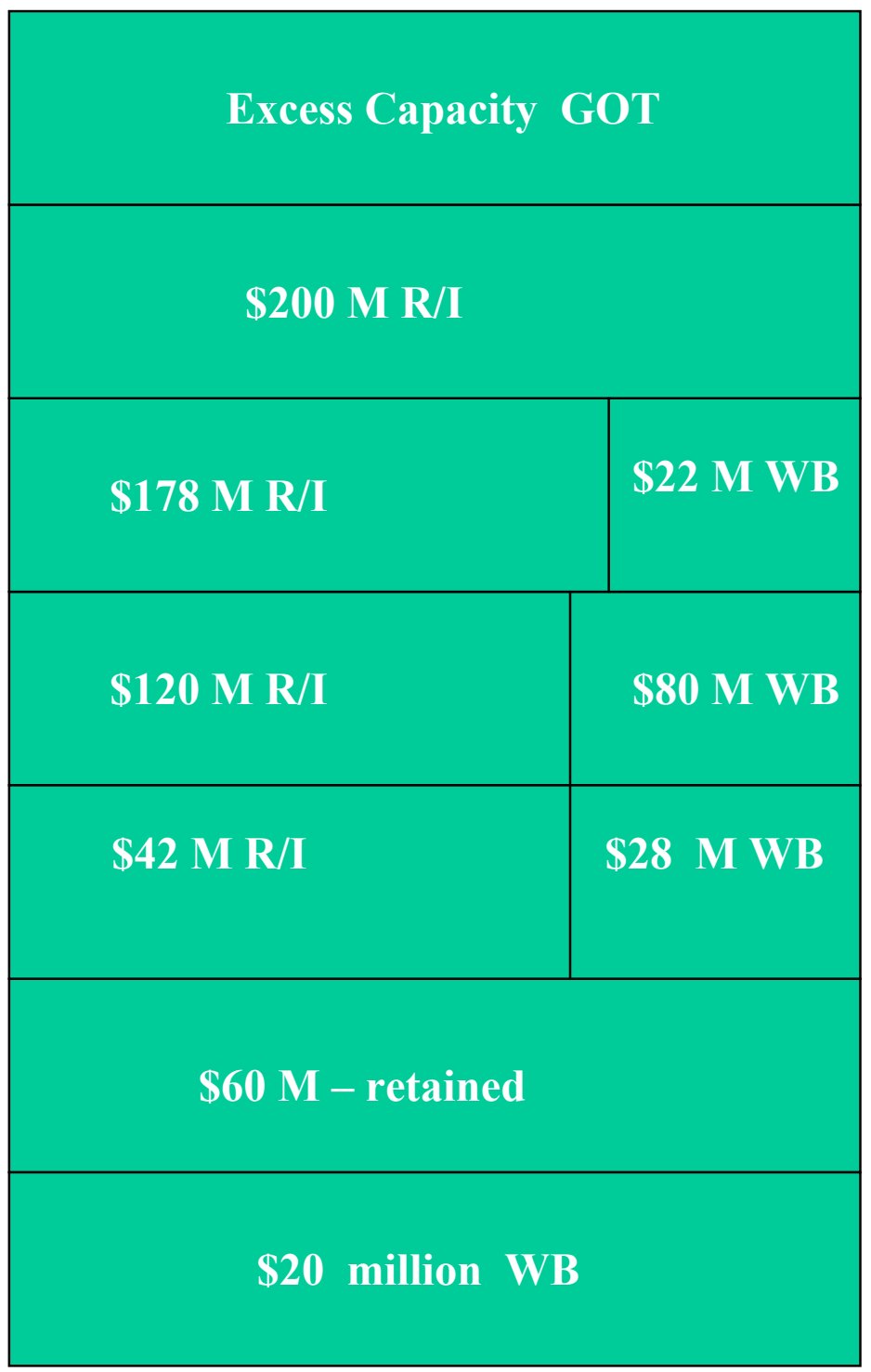

